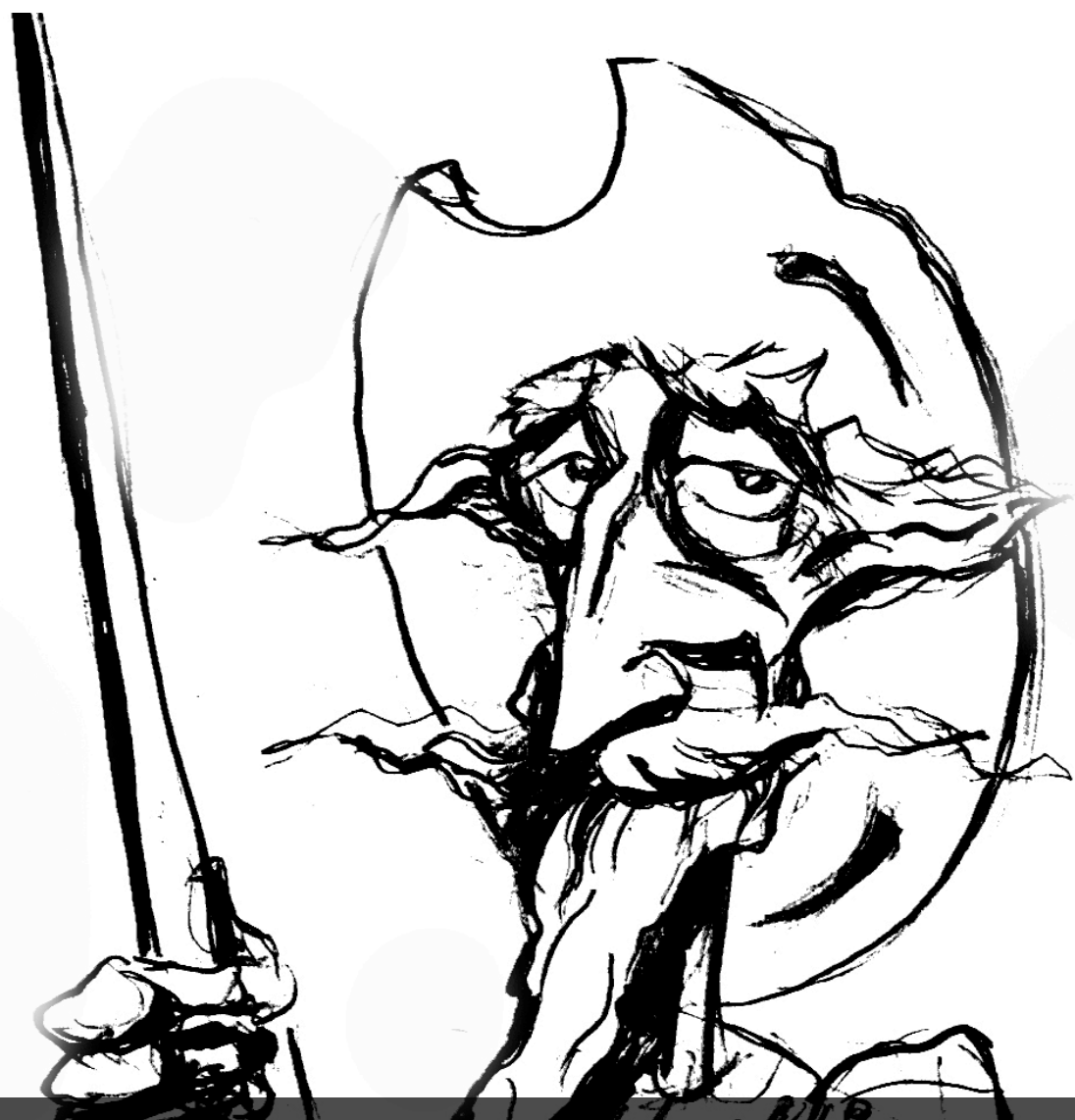

Ciudadanos y soldados en el debate de la Ley sobre el Servicio Militar Voluntario en la Argentina democrática

[Germán Soprano] 


\section{Ciudadanos y soldados en el debate de la Ley sobre el Servicio Militar Voluntario en la Argentina democrática*}

\section{Citizens and Soldiers in the Debate on the Law about Voluntary Military Service in Democratic Argentina}

GERMÁN SOPRANO

\section{Resumen}

Este artículo tiene por objeto las concepciones de ciudadano y soldado presentadas en el debate parlamentario sobre la Ley de Servicio Militar Voluntario. Comprende: 1) los proyectos que contribuyeron a la elaboración de un amplio consenso parlamentario; 2) el reconocimiento de demandas de los ciudadanos contra el servicio militar obligatorio; 3) las comparaciones entre los proyectos de ley de servicio militar de 1901 y 1994; 4) la influencia de la experiencia del terrorismo de Estado en la última dictadura en el resguardo de los derechos humanos del soldado; 5) y la definición de los ciudadanos que pueden ser soldados voluntarios y aquellos exceptuados de la conscripción en circunstancias excepcionales.

\section{Palabras clave}

Ciudadanos - soldados - conscripción - servicio militar voluntario - Argentina

\begin{abstract}
This article aims to conceptions of citizen and soldier presented in the parliamentary debate on the law about voluntary military service. It analyses: 1) the projects contributing to the development of a broad parliamentary consensus; (2) the recognition of demands of the citizens against the compulsory military service; (3) comparisons between 1901-1994 military service bills; (4) the influence of the experience of State terrorism in the last dictatorship in the protection of the human rights of the soldier; and 5) the definition of citizens who may be volunteer soldiers and those exempted from conscription in exceptional circumstances.
\end{abstract}

\section{Key words}

Citizens - soldiers - conscription - voluntary military service - Argentine

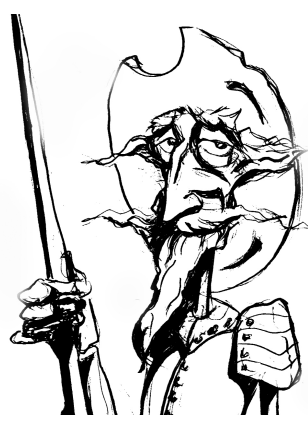

Recibido con pedido de publicación el 10 de diciembre de 2016

Aceptado para su publicación el 5 de febrero de 2016

Versión definitiva recibida el 3 de marzo de 2016

Germán Soprano, Consejo Nacional de Investigaciones Científicas y Técnicas, Universidad Nacional de Quilmes y Universidad Nacional de La Plata, Argentina; e-mail: gsoprano69@gmail.com

\footnotetext{
* Deseo expresar mi agradecimiento a editores de la revista y evaluadores anónimos de este artículo por los comentarios señalados, pues permitieron mejorar la exposición de sus argumentos y conclusiones.

Esta obra se publica bajo licencia Creative Commons. Atribución-NoComercial-CompartirIgual 4.0 Internacional

$(\mathrm{Cc}) \mathbf{E Y - N C - S A}$

Soprano, Germán "Ciudadanos y soldados en el debate de la Ley sobre el Servicio Militar Voluntario en la Argentina democrática", Prohistoria, Año XIX, núm. 25, jun. 2016, pp. 105-133.
} 


\section{Introducción}

En la década de 1970 Estados Unidos modificó su sistema de reclutamiento de tropa de las Fuerzas Armadas tras la derrota en la guerra de Vietnam. En 1973 reemplazó el sistema de conscripción por uno de soldados voluntarios, pero mantuvo la obligación de los ciudadanos de 18 años de inscribirse en el Selective Service System destinado a completar -previa autorización del Congreso- los requerimientos de personal militar cuando las necesidades de la defensa lo demandasen. Desde la década de 1990 países de Europa Occidental y del resto del mundo también abandonaron el sistema de conscripción, originando cambios en las instituciones castrenses con la plena profesionalización de su personal, así como en las relaciones de estas con sus sociedades cuando se dejó de concebir el servicio militar como atributo de la ciudadanía. ${ }^{1}$

La suspensión de la conscripción en la Argentina se produjo en diciembre de 1994 por la Ley 24.429 de Servicio Militar Voluntario. ${ }^{2}$ Contra arraigadas nociones de sentido común, esa ley no abrogó o derogó totalmente el servicio militar obligatorio, sino que lo suspendió y reemplazó por una prestación efectuada por propia decisión de los ciudadanos e incorporó por primera vez a las mujeres. ${ }^{3}$ Las modificaciones introducidas por esta nueva

1 Un artículo precursor de Charles Moskos analizó el impacto del pasaje del sistema de conscripción obligatoria al de voluntarios en la configuración de las organizaciones castrenses y perfiles sociales de los militares en los Estados Unidos. Para el caso de Europa nos servimos del Bernard Boëne, quien comprendió el proceso de profesionalización integral de las Fuerzas Armadas con el abandono del sistema de conscripción en Bélgica en 1992, Países Bajos en 1993, Francia en 1996, España 1997 e Italia en 1999. MOSKOS, Charles "The All-Volunteer Military: Calling, Profession, or Occupation?" Parameters vol.7 N¹1, 1977, pp. 23-31. BOËNE, Bernard “La professionnalisation des armées: contexte et raisons, impact fonctionnel et sociopolitique", Revue Francaise de Sociologie 44-4, 2003, pp. 647.693.En el Cono Sur americano además de la Argentina, Uruguay y Chile poseen servicio militar voluntario. Este último país tiene un sistema mixto por el cual los requerimientos de tropa se cubren con voluntarios y, en caso de no alcanzarse la cantidad necesaria, se completa por conscripción sorteando a ciudadanos del sexo masculino.

${ }^{2}$ La Ley de Servicio Militar Voluntario 24.429 fue aprobada el 14 de diciembre de 1994, promulgada el 5 de enero de 1995, publicada en el Boletín Oficial el 10 de enero y reglamentada por decreto 978 del 6 de julio de 1995, publicado en el Boletín Oficial el 12 de julio de ese año. Esta ley derogó el decreto-ley 17.531 de Servicio Militar del gobierno de facto del general Juan Carlos Onganía -del 13 de noviembre de 1967, publicado en el Boletín Oficial el 16 de noviembre- y sus actualizaciones.

3 El artículo 19ำ de la Ley 24.429 consigna en qué circunstancias y por medio de qué procedimientos institucionales se habilita el recurso a la conscripción: "En el caso excepcional que no se llegaran a cubrir con soldados voluntarios los cupos fijados de acuerdo con el artículo 3, el Poder Ejecutivo podrá convocar, en los términos establecidos por la ley 17.531, a los ciudadanos que en el año de la prestación cumplan 18 años de edad y por un período que no podrá exceder de un año. Para realizar la convocatoria el Poder Ejecutivo deberá previamente requerir la autorización por ley del Congreso Nacional, expresando las circunstancias que motivan la solicitud y las razones por las cuales no pudieron cubrirse los cupos pertinentes". http://infoleg.mecon.gov.ar/ Consultado en línea el 01 de junio de 2015. 
normativa habilitaron un proceso de desmilitarización de la sociedad argentina, cambios en su política de defensa y su instrumento militaren democracia. ${ }^{4}$ Entre las causas para explicar el fin de la conscripción se han destacado:

1. La devaluación del poder de las conducciones militares tras la derrota en la guerra de Malvinas y la crisis por colapso del gobierno del autodenominado "Proceso de Reorganización Nacional". 5 Y, posteriormente, la afirmación de la subordinación de las Fuerzas Armadas a las autoridades civiles democráticas tras la represión del último "levantamiento carapintada" conducida el 3 de diciembre de 1990 por el general Martín Antonio Balza siendo subjefe del Estado Mayor General del Ejército. ${ }^{6}$

2. La significativa disminución del número de conscriptos desde 1984 como parte de una estrategia gubernamental de restricción del poder militar, así como la aplicación de políticas de ajuste presupuestario en el área de defensa y la reestructuración de las Fuerzas Armadas en el marco de la denominada "modernización del Estado". ${ }^{7}$

\footnotetext{
${ }^{4}$ Sobre esto último véase: LAFFERRIERE, Guillermo y SOPRANO, Germán "El servicio militar voluntario en las Fuerzas Armadas Argentinas entre el final del siglo XX y principios del XXI", en: Conjuntura Austral vol. 5, no 24, Porto Alegre, 2014, pp. 17-45.

${ }^{5}$ Sobre las características específicas de la transición a la democracia en la Argentina en el contexto del Cono Sur remito al estudio clásico de: O'DONNELL, Guillermo - SCHMITTER, Philippe y WHITEHEAD, Lawrence (comps.) Transiciones desde un gobierno autoritario, Ediciones Paidós, Barcelona, 1994. Para un análisis de los efectos duraderos de esa transición en la definición de la política de defensa nacional y el diseño de las Fuerzas Armadas Argentinas: SAIN, Marcelo Los votos y las botas. Estudios sobre la defensa nacional y las relaciones civil-militares en la democracia argentina, Prometeo, Buenos Aires, 2010; LAFFERRIERE, Guillermo y SOPRANO, Germán El Ejército y la política de Defensa en la Argentina del siglo XXI, Prohistoria, Rosario, 2015.

${ }^{6}$ SAIÍN, Marcelo Los levantamientos carapintada, 1987-1991, Centro Editor de América Latina, Buenos Aires 1994; LÓPEZ, Ernesto Ni la ceniza ni la gloria. Actores, sistema político y cuestión militar en los años de Alfonsín, Universidad Nacional de Quilmes, Bernal 1994; PUCCIARELLI, Alfredo "La República no tiene Ejército. El poder gubernamental y la movilización popular durante el levantamiento militar de Semana santa", en: PUCCIARELLI, Alfredo (coord.) Los años de Alfonsín ¿El poder de la democracia o la democracia del poder?, Siglo Veintiuno Editores, Buenos Aires, 2006, pp. 115-152.

${ }^{7}$ La comparación de la cantidad de conscriptos reclutados en el Ejército en la década de 1970 y de voluntarios desde 1995 hasta 2010, permite constatar que: 1) Un incremento progresivo de la tropa -con oscilaciones- desde 59.664 conscriptos en 1973 hasta 72.886 en 1984. 2) Con el gobierno de Raúl Alfonsín se reconoce una tendencia a la disminución de la tropa que incluyó una etapa de marcada retracción de conscriptos desde el techo de 1984 a los 25.328 de 1987. 3) Luego una leve recuperación entre 1988-1990 entre unos 29.000 o 29.060. 4) Seguidamente un recorte abrupto a unos 9.924 en 1992 y un repunte en los dos años siguientes con 13.413 y 20.000. Se estima que por entonces solo un $7 \%$ de los jóvenes varones de una clase efectuaban el servicio militar obligatorio contra los $2 / 3$ de la clase que -se presupone- lo realizaban en
} 
3. El escenario internacional post-Guerra Fría y el regional de paz y cooperación con Chile y Brasil con los cuales se había mantenido hipótesis de conflicto durante el siglo XX. ${ }^{8}$

4. El crimen del soldado Omar Carrasco en marzo de 1994 en una unidad militar del Ejército, que tuvo por efecto una rotunda afirmación de demandas de movimientos sociales y de opinión pública contrarios a la conscripción. ${ }^{9}$

En los debates parlamentarios sobre el proyecto de Ley de Servicio Militar Voluntario los legisladores reconocían que era preciso abrogar, suspender o modificar el sistema de conscripción. Destacaban los cambios producidos en la Argentina de fines del siglo XX en las concepciones del ciudadano y del soldado como una causa fundamental de las reformas normativas que debían concretarse con premura. Sin embargo, los científicos sociales han prestado escasa atención a esas concepciones en los discursos de

décadas pasadas. 5) El sistema de voluntarios impuso una drástica reducción de la tropa con 15.848 en 1995, cantidad que permanece relativamente estable hasta alcanzar un aumento de 18.946 en 2009 y 17.418 en 2010. Asimismo, la participación de los conscriptos respecto de la población total en los años 1980, 1991, 2001 y 2010 era, respectivamente, de 0,36\%, 0,31\%, 0,04\% y $0,05 \%$. Si comparamos los conscriptos con la población masculina en 1980 y 1991 reconoceremos un leve incremento del $0,73 \%$ y $0,63 \%$ que, sin embargo, no es un indicador sustantivo de incorporación y movilización militar de ciudadanos. LAFFERRIERE, Guillermo y SOPRANO, Germán "El servicio militar voluntario..." cit.

8 Para un análisis de los cambios en las relaciones exteriores de Argentina con Brasil y Chile, véase: LACOSTE, Pablo La imagen del otro en las relaciones de Argentina y Chile (1534-2000), Fondo de Cultura Económica, Santiago de Chile, 2003; RUSSELL, Roberto y TOKATLIAN, Juan Gabriel El lugar de Brasil en la política exterior Argentina, Fondo de Cultura Económica, Buenos Aires, 2003; RAPOPORT, Mario y MADRID, Eduardo Argentina-Brasil. De rivales a aliados: política, economía y relaciones bilaterales, Capital Intelectual, Buenos Aires, 2011. Estudios sobre esas relaciones en las políticas de defensa: RUNZA, Ricardo "Las relaciones argentino-chilenas de defensa. Análisis y evaluación desde la perspectiva del Comité Permanente de Seguridad", Lateinamerika Analysen 8, 2004, pp. 137-166; ALVES SOARES, Samuel y SOPRANO, Germán "Políticas de defesa de Argentina e Brasil no começo do século XXI: entre a confiança mútua e as culturas estratégicas em dissonância", en: DOS PASSOS, R. et al (eds), Relações Internacionais Contemporâneas: novos protagonistas e novas conjunturas, Universidade Estadual Paulista, Marilia, 2014, pp. 187-210; LAFFERRIERE, Guillermo y SOPRANO, Germán "La cooperación del Ejército argentino y brasileño desde fines del siglo XX", en: Revista Brasileira de Estudos de Defesa, no2, Porto Alegre. Brasil, 2015, pp. 154-167.

${ }_{9}$ GARAÑO, Santiago "El Frente Opositor al Servicio Militar Obligatorio. El debate sobre la conscripción y el activismo en derechos humanos en la post-dictadura argentina", Revista Sociedad Latinoamericana, núm. 1.

http://sociedadlatinoamericana.bligoo.com/content/view/1545868/El-Frente-Opositor-al-

Servicio-Militar-Obligatorio-en-la-pots-dictadura-argentina.html Consultado en línea 01 de junio de 2015. Por motivos de disponibilidad de espacio no presentaremos los sucesos relacionados con el crimen del soldado Omar Carrasco. 
diputados de diferentes partidos políticos, en sus proyectos y en el articulado de la Ley 24.429. ${ }^{10}$

La razón por la cual no fueron objeto de un adecuado abordaje académico puede ser resultado del desconocimiento de su incidencia en la definición de la política de defensa y su instrumento militar y, más ampliamente, en sus relaciones con los sentidos y formas de ejercicio de la ciudadanía;11 o bien por haber comprendido aquellos debates desde unas perspectivas políticas e ideológicas que otorgaron centralidad más bien excluyente a la depreciación del poder político y legitimidad castrense, al impacto político del crimen del soldado Carrasco, o a la eficacia de las políticas neoliberales de reforma del Estado y ajuste presupuestario sobre las Fuerzas Armadas.

${ }^{10}$ Contrariamente existe abundante literatura sobre las relaciones entre ciudadanía, milicias y ejército de línea en el Río de la Plata y la Argentina del siglo XIX; entre otros: CANSANELLO, Orestes De súbditos a ciudadanos. Ensayo sobre las libertades en los Orígenes republicanos. Buenos Aires. 1810-1852. Buenos Aires. Imago Mundi, 2003; SÁBATO, Hilda “¿Quién controla El poder militar? Disputas en torno de la formación del Estado en el siglo XIX", en: MORENO, O. (coord.), La construcción de La Nación Argentina. El rol de las Fuerzas Armadas, Ministerio de Defensa, Buenos Aires, 2010, pp. 125-140. Sin embargo, no se dispone de estudios sistemáticos que hayan comprendido las relaciones entre ciudadanos y soldados en la Argentina del siglo XX y XXI. Tampoco existen trabajos sobre la historia del servicio militar obligatorio en el siglo XX. Por ello, aún continúa siendo una referencia el estudio de: RODRÍGUEZ MOLAS, Ricardo Debate nacional: El servicio militar obligatorio, Centro Editor de América Latina, Buenos Aires, 1983. Recientemente Hugo Quinterno y María Laura Guembe analizaron aspectos significativos del proceso de implementación de esa ley en sus primeros años. QUINTERNO, Hugo Fuego amigo. El Ejército y el poder presidencial en la Argentina (1880-1912), Universidad Abierta Interamericana / Teseo, Buenos Aires, 2014; GUEMBE, María Laura "De la ciudadanía en armas al servicio militar obligatorio", en LORENZ, F. (comp), Guerras de la historia argentina, Ariel, Buenos Aires, 2015, pp. 269-286. Para la década de 1970 se cuenta con: GARAÑO, Santiago "Entre héroes y traidores. Sentidos militares y militantes acerca del rol de los conscriptos en los años 70", Cuadernos de Antropología Social 33, Buenos Aires, 2011; del mismo autor, "Soldados sospechosos. Militancia, conscripción y fuerzas armadas durante los años setenta", Contenciosa, Año 1 núm. 1, 2013, pp. 1-16. Rosana Guber, Federico Lorenz y Andrea Rodríguez se ocuparon de experiencias y memorias de soldados conscriptos en la guerra de Malvinas. GUBER, Rosana De chicos a veteranos. Memorias argentinas de la guerra de Malvinas, Editorial Antropofagia, Buenos Aires, 2004; LORENZ, Federico Las guerras por Malvinas Edhasa, Buenos Aires, 2006 y Malvinas. Una guerra argentina, Sudamericana, Buenos Aires, 2009; RODRÍGUEZ, Andrea "De veteranos 'verdaderos' y 'truchos'. Análisis de las definiciones de 'ex-combatiente/veterano de guerra' de los miembros del Apostadero Naval Malvinas en el Conflicto del Atlántico Sur", Anuario del Centro de Estudios Históricos "Prof. Carlos S. A. Segreti", vol. 10, Córdoba, 2010, pp. 303-323.

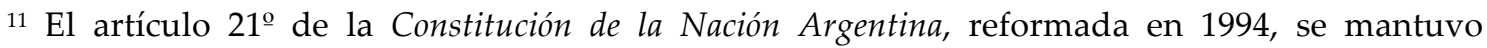
inalterado: "Todo ciudadano argentino está obligado a armarse en defensa de la Patria y de esta Constitución, conforme a las leyes que al efecto dicte el Congreso y a los decretos del Ejecutivo nacional. Los ciudadanos por naturalización son libres de prestar o no este servicio por el término de diez años contados desde el día que obtengan su carta de ciudadanía". Repárese que el texto dice "está obligado" y no que "tiene derecho". http://infoleg.mecon.gov.ar/ Consultado en línea el 01 de junio de 2015. 
En consecuencia, este artículo tiene por objeto las concepciones del ciudadano y del soldado presentadas por los legisladores en el debate desplegado en las sesiones ordinarias del 14 y 21 de septiembre de 1994 en la Cámara de Diputados en torno del proyecto de Ley de Servicio Militar Voluntario. ${ }^{12}$ Comprenderemos: 1) los proyectos de ley que contribuyeron a la elaboración de un amplio consenso parlamentario; 2) el reconocimiento de demandas de los ciudadanos contra el servicio militar obligatorio; 3) las comparaciones entre los proyectos de ley de servicio militar de 1901 y 1994; 4) la influencia de la experiencia del terrorismo de Estado en la última dictadura en el resguardo de los derechos humanos del soldado; 5) y la definición de los ciudadanos que pueden ser soldados voluntarios y aquellos exceptuados de la conscripción en circunstancias excepcionales.

\section{Proyectos de Ley de Servicio Militar Voluntario}

La Ley 24.429de Servicio Militar Voluntario contaba entre sus antecedentes los proyectos de legisladores peronistas - del Partido Justicialista (PJ)- y radicales de la Unión Cívica Radical (UCR) - elaborados tras el asesinato del soldado Omar Carrasco por:

- Víctor Peláez (UCR/Neuquén) con los diputados radicales Pedro Jorge Galante (Entre Ríos), Ana Ida Piccinini (Río Negro), Atilio Oscar Viglione (Chubut) y Margarita María Sobrino (Córdoba) como co-firmantes. ${ }^{13}$

- Ana Raquel Kessler (PJ/Capital Federal) con el diputado justicialista Antonio Erman González (Capital Federal) como cofirmante.

- Miguel Ángel Toma (PJ/Capital Federal) con los diputados justicialistas Carlos A. Romero (La Rioja), Jorge Rubén Matzkin (La Pampa), Marcela M. Durrieu (Buenos Aires), Oscar Lamberto (Santa Fe), Eduardo Camaño (Buenos Aires), Miguel H. D'Alessandro (Córdoba), Jorge C. Daud (Entre Ríos), Jorge M. Argüello (Capital Federal), Miguel Ángel García Moreno (Capital Federal) y Carlos Soria (Río Negro) como co-firmantes.

\footnotetext{
${ }_{12}$ Nos ocupamos de las sesiones ordinarias de los días 14 y 21 de septiembre de 1994 en la Cámara de Diputados de la Nación porque en ellas se produjeron las definiciones más extensas e intensos debates entre los legisladores. Por el contrario, el tratamiento del proyecto en sesiones ordinarias de la Cámara de Senadores de la Nación fue breve.

${ }^{13}$ En el desarrollo del artículo se citará entre paréntesis el partido político al que pertenece el diputado nacional y la jurisdicción electoral por la que fue electo.
} 
- Antonio Berhongaray (UCR/La Pampa).

- José Manuel Corchuelo Blasco (PJ/Chubut).

- Ramón Francisco Giménez (PJ/Formosa) con los diputados justicialistas Miguel Ángel Toma (Capital federal) y Miguel Ángel Pichetto (Río Negro) como co-firmantes.

- Jesús Rodríguez (UCR/Capital Federal).

- Rodolfo Campero (UCR/Tucumán).

También fueron incorporados otros proyectos de 1993 de los diputados:

- José Gabriel Dumón y otros de la UCR.

- Orlando Zicarelli del PJ. ${ }^{14}$

En la sesión ordinaria del 18 de agosto de 1994 los diputados de diferentes partidos políticos que integraban la Comisión de Defensa Nacional consensuaron un proyecto. Conforme a ese acuerdo, el 30 de agosto la Comisión de Presupuesto y Hacienda de la Cámara de Diputados aprobó tres proyectos de Miguel Ángel Toma y otros, de Ana Raquel Kessler, y de Antonio Berhongaray- y puso en consideración otros siete -de Orlando Zicarelli, de José Gabriel Dumón y otros, de José Manuel Corchuelo Blasco, de Víctor Peláez y otros, de Ramón F. Giménez y otros, de Jesús Rodríguez y otros, y de Rodolfo Campero. ${ }^{15}$

En la sesión ordinaria del 14 de septiembre, Toma ofició como informante de la Comisión de Defensa Nacional y presentó el proyecto de Ley de Servicio Militar Voluntario destacando: 1) La incorporación al servicio militar de hombres y mujeres, terminando con la "discriminación" de estas últimas "que nada tiene que ver con el mundo de hoy ni con los actuales requerimientos de la defensa". 2) La jerarquización de los aprendizajes de los soldados voluntarios recibiendo "capacitación militar" y "formación en técnicas

\footnotetext{
${ }^{14}$ En el dictamen de la Comisión de Defensa Nacional y en las intervenciones en sesiones ordinarias del 14 de septiembre se hizo referencia a un proyecto que había alcanzado media sanción en 1992 consensuado por los diputados Victorio Bisciotti (UCR) y Miguel Ángel Toma (PJ), dos referentes en el debate y elaboración de la Ley de Defensa Nacional de 1988; y también a otros cuarenta proyectos de ley que desde diciembre de 1983 habían propuesto la reforma, eliminación o suspensión de la conscripción y/o el diseño de un sistema voluntario. La existencia de esa abundante cantidad de proyectos confirman la importancia que tenía esta cuestión en la agenda política democrática.

${ }^{15}$ Para un análisis de los proyectos de Kessler y González, de Toma y otros, y de Berhongaray: LAFFERRIERE, Guillermo y SOPRANO, Germán "El servicio militar voluntario en las Fuerzas Armadas Argentinas...", cit.
} 
y oficios que luego podrán aplicar en el ámbito laboral civil". 3) El otorgamiento de "ventajas" tras la finalización del servicio en el acceso al empleo en la administración pública, a planes de vivienda, a organismos de seguridad y como personal de cuadros de las Fuerzas Armadas. 4) El resguardo de los "derechos humanos propios de la persona y la expresa prohibición de cumplir con tareas ajenas al servicio que desnaturalizarían su condición de soldados" y las garantías de la "absoluta libertad de conciencia y la no discriminación política, ideológica o religiosa". Se ofrecía asimismo una amnistía a los infractores del servicio militar obligatorio y se eximía a los ciudadanos que habían solicitado prórroga en su cumplimiento para completar sus estudios universitarios.

Para Toma el proyecto respondía a "requerimientos de la familia y la juventud" y a un extendido consenso situado "por encima de las pertenencias partidarias y de los matices políticos", tal como correspondía a circunstancias en las que los "reclamos de la sociedad" excedían "la política de partido para constituirse en una política de Estado que la sociedad demanda". ${ }^{16}$ Para alcanzar ese resultado -decía- fue preciso "despojarnos de preconceptos e influencias" respecto de los asuntos de defensa y de las Fuerzas Armadas y lograr el "más amplio consenso", tal como ocurrió con la sanción de la Ley 23.554 de Defensa Nacional (1988) y la Ley 24.059 de Seguridad Interior (1991). ${ }^{17}$ Es que la Ley de Servicio Militar Voluntario evidenció -más allá de las diferencias que mostraremos a continuación- un acuerdo básico en la dirigencia política: era necesario suspender el sistema de conscripción y proponer un sistema de reclutamiento con ciudadanos que se ofrecieran como soldados en forma voluntaria.

\section{Demandas ciudadanas contra el servicio militar obligatorio}

En las sesiones ordinarias del 14 y 21 de septiembre de 1994 los diputados manifestaron que el asesinato del soldado Omar Carrasco fue el detonante que sentó condiciones políticas y sociales para sancionar una ley que suspendiera o derogase el servicio militar obligatorio y conformara un nuevo sistema voluntario. El diputado Jesús Rodríguez (UCR-Capital Federal) expresó que existía una fuerte corriente de opinión en la ciudadanía contraria a la conscripción. Recordaba que una encuesta publicada en septiembre de 1983 ya se indicaba que el $66 \%$ de los argentinos estaba a favor del reemplazo de la conscripción por un sistema voluntario. Pero al mismo tiempo señalaba que el gobierno nacional y los legisladores justicialistas no impulsaban la eliminación del servicio militar obligatorio, sino proponían una "combinación entre un voluntariado fuerte y un servicio obligatorio eventual y de refuerzo", dejando

\footnotetext{
${ }_{16}$ Diario de Sesiones Cámara de Diputados (en adelante: $D S C D$ ), 14 de septiembre de 1994, p. 2175.

${ }^{17}$ DSCD, 14 de septiembre de 1994, pp. 2153-2154.
} 
abierta la re-implementación de la conscripción obligatoria cuando no se cubriera el cupo necesario de soldados voluntarios. ${ }^{18}$ Esta afirmación era cierta, pues -como ya señaláramos- la conscripción no fue abrogada en 1994 sino suspendida.

El diputado Héctor Polino (Unidad Socialista/Capital Federal) señaló que el proyecto de ley reconocía como antecedentes otros proyectos legislativos y el papel cumplido en la sociedad civil por el Frente Opositor al Servicio Militar Obligatorio (FOSMO). Pero dijo también que si no se hubiera hecho público el asesinato del soldado Carrasco -que conmovió a la "opinión pública" - no se habría alcanzado un amplio consenso político a favor del servicio militar voluntario. ${ }^{19}$ Por ello y a modo de homenaje, agregaba, la ley debía recordarse con el nombre del conscripto. Sus dichos despertaron aplausos de otros legisladores, entre ellos, el diputado Luis Nicolás Polo (MODIN/Provincia de Buenos Aires)que también adhirió al "homenaje" en "memoria del soldado Carrasco". ${ }^{20} \mathrm{Su}$ adhesión es bien expresiva de cuán amplio era el reconocimiento atribuido por los legisladores a la "injusta muerte" de Carrasco como detonante del fin de la conscripción: Polo era un teniente coronel del Ejército en situación de retiro, uno de los líderes del movimiento de "militares carapintada", y miembro de un partido nacionalista de derecha -el MODINconformado por estos últimos. ${ }^{21}$

Pero no todos los legisladores compartían esas apreciaciones. Otra era la perspectiva de los diputados del partido de liberal-conservador Unión de

18 DSCD, 14 de septiembre de 1994, pp. 2173 y 2169.

${ }^{19}$ El recurso analítico a las categorías derecha e izquierda para definir las orientaciones políticas e ideológicas de los partidos políticos mencionados en este artículo tiene una eficacia interpretativa limitada, pues su empleo puede ser relativamente adecuado para caracterizar los posicionamientos de diputados nacionales de Unidad Socialista o del Frente Grande como partidos de izquierda, o bien a la Unión de Centro Democrático-UCeDe, el Movimiento por la Dignidad y la Independencia-MODIN o a Fuerza Republicana como partidos de derecha. Sin embargo carece de precisión para comprender al Partido Justicialista-PJ o la Unión Cívica Radical-UCR donde conviven liderazgos y grupos de una u otra orientación. Asimismo, en el caso de los legisladores socialistas y del Frente Grande, “izquierda” quizá pueda considerarse como una categoría nativa; pero este criterio de clasificación que enfatiza las auto-adscripciones de los actores sociales no es necesariamente válido para la UCeDe, MODIN o Fuerza Republicana, pues sus integrantes no se autodefinían públicamente como de "derecha", aun cuando los científicos políticos no dudarían en clasificarlos como miembros de partidos de esa orientación. Véase: ABAL MEDINA (h), Juan Manuel y SUÁREZ CAO, Julieta “La competencia partidaria en la Argentina: sus implicancias sobre el régimen democrático", en: CAVAROZZI, M. y ABAL MEDINA, J. M. (comps.), El asedio a la política. Los partidos latinoamericanos en la era neoliberal, Konrad Adenauer Stiftung / Homo Sapiens, Rosario, 2002, pp. 163-186.

${ }^{20}$ DSCD, 14 de septiembre de 1994, pp. 2187-2188.

21 Sobre la participación de los "militares carapintada" en política: LACOSTE, Pablo et al Militares y política. 1983-1991, Centro Editor de América Latina, Buenos Aires, 1993; ADROGUÉ, Gerardo "Los ex-militares en política. Bases sociales y cambios en los patrones de representación política”. Desarrollo EconómicoVol.33 núm. 131, Buenos Aires, 1993, pp. 425-456. 
Centro Democrático-UCeDe. ${ }^{22}$ Para el diputado Álvaro Alsogaray (Capital Federal) -histórico líder de ese partido- el crimen de Carrasco era un hecho aberrante. Su partido estaba a favor de la necesidad de sancionar la ley en debate, si bien consideraba más propicio un sistema de conscripción universal temporalmente reducido y combinado con soldados voluntarios. Pensaba que no era conveniente implementar un nuevo sistema de reclutamiento con voluntarios bajo las "presiones sociales y políticas" provocadas por el "shock' emocional" que experimentaba el país. ${ }^{23} \mathrm{Su}$ co-partidario el diputado Francisco Durañona y Vedia (UCeDe/Provincia de Buenos Aires) coincidía con él y sostenía el carácter absolutamente excepcional de los "hechos luctuosos" ocurridos en la unidad militar del Ejército donde fue asesinado Carrasco, pues "no provenían de situaciones institucionales, sino de conductas o comportamientos indeseables que existen en todas las instituciones o ámbitos". ${ }^{24}$

La percepción de un clima social favorablemente entusiasta a la derogación de la conscripción también era cuestionada por el diputado por la provincia de Tucumán del partido de derecha Fuerza Republicana, Antonio Domingo Bussi, cuando reconocía con hastío y aun repugnancia la existencia de "cientos de pasacalles y avenidas porteñas en los que se despide sarcásticamente al servicio militar obligatorio y se agradece al potencial autor de la medida". ${ }^{25}$ Dos diputados nacionales pertenecientes a los partidos políticos mayoritarios, el PJ y la UCR, contestaron los dichos de Bussi. El diputado José Manuel Corchuelo Blasco (PJ/Chubut) afirmó que el proyecto de ley era una sentida demanda de la "juventud argentina y de las madres y familias argentinas", pues el "caso del soldado Carrasco significó la gota que

\footnotetext{
${ }^{22}$ La UCeDe era un partido liberal conservador creado en 1982. En la década de 1990 integró la coalición política gobernante durante la presidencia nacional del justicialista Carlos Menem.

${ }^{23}$ DSCD, 14 de septiembre de 1994, p. 2187.

${ }^{24}$ DSCD, 14 de septiembre de 1994, p. 2220.

${ }^{25}$ DSCD, 14 de septiembre de 1994, p. 2193. Bussi fue comandante del "Operativo Independencia" desde diciembre de 1975. Tras el golpe de Estado del 24 de marzo de 1976 estuvo a cargo del poder ejecutivo provincial de Tucumán hasta el año 1978. En democracia fue procesado por crímenes de lesa humanidad, pero se benefició por la Ley 23.492 de Punto Final que prescribió la caducidad de acciones penales en su contra. Ya en situación de retiro, en 1987 comenzó su participación política en Tucumán incorporándose al partido conservador Defensa Provincial-Bandera Blanca y creando luego su propio partido Fuerza Republicana. En 1995 fue electo gobernador de esa provincia por el voto popular. Sobre la trayectoria política de Bussi y, especialmente, el consenso político que suscitó en la sociedad tucumana, véase: CRENZEL, Emilio "Tucumán: la memoria social y la emergencia del bussismo", en: I. Izaguirre (comp. ) Estudios de Sociología, Eudeba, Buenos Aires, 1998, pp. 321-347. CRENZEL, Emilio "Memorias de la dictadura: los desaparecidos y el voto al General Bussi en Tucumán, Argentina", Revista Internacional de Filosofía №14, 1999, pp. 15-29. ISLA, Alejandro "Los apoyos de Bussi. Valores domésticos, espacios públicos en el presente tucumano", en: M. Svampa (ed.) Desde abajo. Las transformaciones de las identidades sociales, Universidad Nacional de General Sarmiento / Editorial Biblos, Buenos Aires, 2000, pp. 209-242.
} 
desbordó el vaso en una Argentina que viene desde hace mucho tiempo reclamando un cambio en materia de servicio militar obligatorio". ${ }^{26} \mathrm{Y}$ el diputado Víctor Peláez (UCR/Neuquén) señaló que la presentación de varios proyectos de ley de suspendiendo o abrogando el servicio militar obligatorio e implementando un nuevo régimen de voluntarios respondía a la voluntad de los legisladores de resolver problemas históricos y estructurales del sistema de conscripción puestos en evidencia por aquel crimen. Peláez incluso no dudaba en definir la conscripción como un régimen de "esclavitud":

“Qué pasó con Carrasco? Murió ¿Quién murió? Un esclavo, el
último esclavo. Lo castigaron, y al hacerlo se les fue la mano y
lo mataron. Tuvimos que llegar a hacer morir al último esclavo
para recapacitar y ver los signos de los tiempos ¿No nos bastaba
ver cómo festejaban los muchachos que rechazaban el servicio
militar obligatorio? No; tuvo que morir Carrasco [...] Propongo
que en este caso el proyecto de ley en consideración quede
perpetuado con un nombre: la ley Carrasco (aplausos)” (DSCD
14/09/94:2201).

Tal apreciación negativa de la conscripción fue reforzada por la diputada Graciela Fernández Meijide del Frente Grande (Capital Federal) para quien el servicio militar obligatorio había fomentado "hechos aberrantes" que no fueron excepcionales -como sostuvieran los legisladores de la UCeDe- sino consecuencia de su concepción e implementación. ${ }^{27}$ Por ello -decía- los ciudadanos promovieron la "formación de un frente" en su contra, el FOSMO, cuando "la sociedad se empezó a organizar en democracia". Para esta diputada el asesinado de Carrasco solo "aceleró" un debate que ya estaba instalado en la sociedad argentina. ${ }^{28}$

Por último, para el diputado Víctor Peláez, la conscripción no solo era una carga abusiva pesando sobre el ciudadano, sino una completamente inútil para la defensa contemporánea, pues en los nuevos escenarios internacionales y con sistemas de armas complejos, las Fuerzas Armadas requerían de tropa compuesta exclusivamente por soldados profesionales. ${ }^{29}$ Del mismo modo, el diputado Antonio Berhongaray (UCR/La Pampa) entendía que los cambios promovidos por el proyecto seguían el ejemplo de la modernización y profesionalización plena de las Fuerzas Armadas de los Estados Unidos, países del Commonwealth y miembros de la OTAN. En su opinión, sin embargo, en la Argentina ese cambio había sido desencadenando por el insuficiente

\footnotetext{
${ }^{26} D S C D, 14$ de septiembre de 1994, p. 2195.

${ }^{27}$ El Frente Grande surgió como una coalición de partidos creada en 1993 oponiéndose a las políticas del gobierno nacional del presidente Carlos Menem e inmediatamente se constituyó como partido político.

${ }^{28}$ DSCD, 14 de septiembre de 1994, p. 2202.

${ }^{29} D S C D, 14$ de septiembre de 1994, p. 2201.
} 
desempeño en combate de los conscriptos -a pesar de "su heroísmo"- en "la gloriosa gesta de Malvinas" y el "desgraciado hecho del soldado Carrasco". ${ }^{30}$

\section{Ciudadanos y soldados a principio y fines del siglo $X X$}

El diputado Miguel Ángel Toma definía la Ley de Servicio Militar Voluntario como expresión del fin de una época abierta en 1901 por la Ley de Servicio Militar Obligatorio. Esta última ley -decía- había terminado con las iniquidades sociales producidas en el siglo XIX por las "levas" militares, dando lugar con la conscripción a un sistema universal y democrático que distribuía equitativamente las obligaciones ciudadanas de la defensa. ${ }^{31}$ Pero -continuabala sociedad argentina de fines del siglo XX había experimentado cambios socioeconómicos, políticos y culturales que impactaron sobre las percepciones y experiencias de los ciudadanos sobre la conscripción. Se imponía entonces una innovación legislativa que creara un sistema fundado en ciudadanos que decidieran incorporarse en forma voluntaria como soldados profesionales. ${ }^{32}$

Para la diputada Ana Raquel Kessler (PJ-Capital Federal) en las postrimerías del siglo XX el sistema de conscripción había derivado en una nueva inequidad ciudadana, en la medida en que la prestación recaía en un número reducido de jóvenes de una "clase". ${ }^{33}$ Por ello decía que:

“El proyecto que estamos considerando beneficiará a la sociedad, a las instituciones mismas y a la Nación. En lo social y familiar permite planificar mejor y desaparece la falta de igualdad, donde la prestación del servicio se realizaba por el azar de un sorteo que no tenía en cuenta necesidades ni situaciones por las que pasaba el ciudadano, por ende, se transformaba la obligación para todos en la real prestación de

\footnotetext{
${ }^{30}$ DSCD, 14 de septiembre de 1994, p. 2207. Es importante no omitir que las Fuerzas Armadas Argentinas habían elaborado -desde la derrota en la guerra de Malvinas- propuesta de incorporación de un servicio militar voluntario.

${ }^{31} D S C D, 14$ de septiembre de 1994, p. 2176. Ese carácter universal, equitativo y democrático que, según Toma, instauró el sistema de conscripción de 1901 fue puesto en cuestión por investigaciones que se ocuparon de su implementación en las primeras décadas del siglo, señalando la persistencia predominante del reclutamiento entre los sectores populares e, incluso, la subsistencia del "personero" que cumplía la prestación militar por otro ciudadano. QUINTERNO, Hugo Fuego amigo... cit. y GUEMBE, María Laura "De la ciudadanía en armas al servicio militar obligatorio"... cit. No obstante la valiosa contribución de estos autores, como observáramos al comienzo del artículo, se carece de investigaciones empíricas sistemáticas que analicen la evolución cuantitativa y la composición social de los soldados conscriptos a lo largo del siglo $X X$.

${ }^{32}$ DSCD, 14 de septiembre de 1994, p. 2176.

${ }^{33} \mathrm{La}$ "clase" comprendía a todos los ciudadanos del sexo masculino nacidos en un mismo año, a partir de la cual se delimitaba el universo de jóvenes convocados para el servicio militar obligatorio tras la realización de un sorteo.
} 
servicio para unos pocos. Ello fue llevando al sistema a convertirse en una pesada carga para muchas familias y restando al soldado el espíritu y la voluntad necesaria para cumplir con esa obligación". ${ }^{34}$

Para Kessler el sistema de soldados voluntarios era equitativo y permitía profesionalizar la tropa, conformar reservas calificadas para la defensa, concretar una real universalización con el acceso de las mujeres, ofrecer saberes socio-profesionales ulteriormente útiles en los medios laborales civiles al concluir su servicio, y abonarles como soldados "remuneraciones y beneficios justos". ${ }^{35}$ De este modo, no solo percibía el nuevo sistema como socialmente necesario para el país en el contexto defines de siglo $\mathrm{XX}$, sino uno que otorgaba beneficios individuales a los jóvenes. Se ponderaban así los atributos sociales de lo militar como profesión y ocupación antes que la invocación al deber ciudadano y el compromiso moral vocacional históricamente asociados al servicio de conscripción. ${ }^{36}$

Las diferencias entre el ciudadano-soldado voluntario de la nueva ley y el ciudadano-soldado conscripto de la Ley de Servicio Militar Obligatorio resultaban elocuentes en una intervención del diputado Bussi (Fuerza Republicana/Tucumán), quien reivindicó las funciones educativas,

${ }_{34}$ DSCD, 14 de septiembre de 1994, p. 2179.

${ }_{35} D S C D, 14$ de septiembre de 1994, p. 2178. La plenitud de esa integración de las mujeres en las Fuerzas Armadas Argentinas, no obstante, ha sido producto de un largo proceso abierto en la década de 1980 y completado en 2012 con su incorporación como oficiales en las armas de infantería y caballería del Ejército, tal como han demostrado las investigaciones etnográficas de Máximo Badaró, Sabina Frederic, Laura Masson y Germán Soprano. BADARÓ, Máximo Militares o ciudadanos. La formación de los oficiales del Ejército Argentino, Prometeo, Buenos Aires, 2009; del mismo autor, Historias del Ejército Argentino. 1990-2010: democracia, política y sociedad, Edhasa, Buenos Aires, 2013; MASSON, Laura "Las mujeres en las Fuerzas Armadas ¿qué tipo de integración?", en: AA.VV Género y Fuerzas Armadas: Algunos Análisis teóricos y prácticos, Ministerio de Defensa/Fundación Ebert, Buenos Aires, 2010, pp. 61-67; FREDERIC, Sabina Las trampas del pasado: las Fuerzas Armadas y su integración al Estado democrático en Argentina, Fondo de Cultura Económica, Buenos Aires, 2013; FREDERIC, Sabina, MASSON, Laura, SOPRANO, Germán Fuerzas Armadas en democracia. Percepciones de los militares argentinos sobre su reconocimiento, Prohistoria Ediciones, Rosario, 2015.

${ }^{36}$ Para una descripción y análisis de las campañas de reclutamiento de soldados voluntarios a comienzos del siglo XXI, veáse: LAFFERRIERE, Guillermo y SOPRANO, Germán "El servicio militar voluntario en las Fuerzas Armadas Argentinas...", cit. Desde la década de 1990 hasta el presente el énfasis atribuido a las dimensiones profesionales y ocupacionales del individuo por sobre las vocacionales y el deber del ciudadano para con la defensa del país, no solo cobró relevancia en la concepción del soldado voluntario sino también en los perfiles de los oficiales y suboficiales -esto es, el personal del cuadro permanente de las Fuerzas Armadas. FREDERIC, Sabina, MASSON, Laura, SOPRANO, Germán Fuerzas Armadas en democracia... cit. SOPRANO, Germán "Ser militar en la Argentina del siglo XXI: entre una vocación, una profesión y una ocupación", Avá. Revista de Antropología 23, 2014, disponible en: www.scielo.org.ar/scielo.php?script=sci_arttext\&pid=S185116942013000200003\&lng=es\&nrm=is o. 
disciplinarias, moralizadoras, civilizadoras y nacionalizadoras de la conscripción. Así Bussi recuperó un argumento clave de los defensores de esta última: su rol como dispositivo de homogeneización político-cultural de la población y eficaz instrumento de defensa en el proceso de construcción del Estado-Nación. Haciendo valer su condición de "soldado y ciudadano" (era general de división retirado) evocó positivamente aquel servicio militar obligatorio que "educó e instruyó durante nueve décadas de su existencia a millones de jóvenes argentinos" y que:

"Frente a las corrientes migratorias que se sucedieron a principios del siglo, coadyuvó a conformar, cual si fuera un crisol, una identidad nacional, despertando y cultivando en sus descendientes similares sentimientos, hábitos y costumbres. Frente a la heterogeneidad de razas, religiones y costumbres de hijos y nietos de esos inmigrantes, contribuyó a forjar una educación integral y un común amor a la patria y a sus símbolos, incluyendo la alfabetización. Frente a los grandes espacios vacíos de nuestra extensa geografía sirvió como elemento colonizador e integrador y avanzada de la seguridad en los confines de la República. Frente a los potenciales conflictos que afrontó la República hasta mediados del presente siglo posibilitó la conformación de reservas altamente instruidas, con una gran capacidad de movilización y de concentración y una considerable aptitud para la guerra. Para la obligación común de servir a la patria posibilitó a los ciudadanos el primer ejercicio de la práctica democrática de la igualdad ante la ley, cualquiera sea su posición frente a la sociedad". 37

Bussi no se oponía a la nueva ley, pero consideraba que hubiera sido más adecuado optar por una transición de cuatro o cinco años en el que convivieran el sistema de conscriptos y el de soldados voluntarios, pues se permitiría así corregir posibles errores de implementación de este último sistema. Decía que era preciso reconocer que: “Después de recrear en la conciencia ciudadana este sentimiento del servicio militar voluntario sería difícil -diría imposiblereimplantar el servicio militar obligatorio". ${ }^{38}$ Proponía que los ciudadanos que ingresaran como soldados voluntarios debían recibir formación y capacitación válida para su "reinserción en la vida civil", pues solo una minoría continuaría su desempeño en las Fuerzas Armadas como suboficiales. Esa formación y capacitación en saberes y prácticas técnico-profesionales reconvertibles en medios civiles no solo debía satisfacer necesidades individuales utilitarias de los jóvenes voluntarios, sino también para prever que "este hombre preparado

37 DSCD, 14 de septiembre de 1994, p. 2193.

${ }^{38}$ DSCD, 14 de septiembre de 1994, p. 2196. 
para la guerra y para la paz pueda lograr una reinserción natural y conducirse dignamente en la vida"; pues -agregaba- si el Estado no les ofrecía recursos para "reinsertarse", el servicio militar voluntario acabaría creando "hombres frustrados que encontrarían en el manejo de las armas el conocimiento de técnicas y tácticas militares y la posibilidad de ganarse la vida encabezando bandas en el terreno de la delincuencia". ${ }^{39}$

Por su parte, el diputado socialista Héctor Polino recordó el discurso del general Alberto Capdevila en el debate de 1901 denunciado el "carácter militarista de la conscripción". También citó un estudio de 1984 de la Fundación Arturo Illia -vinculada a la UCR-para afirmar que:

"La denominada Reforma Riccheri perseguía dos objetivos que el tiempo demostró que eran contradictorios. Por un lado, quería apartar a los militares de los partidos políticos; por otro lado, transformó al Ejército en una escuela política de nacionalidad para los jóvenes conscriptos. Formalmente excluidos de los partidos políticos, los militares adoptaron una actitud negativa hacia los partidos y hacia el proceso democrático. El modelo democrático que inspiró la reforma alentó a los militares a erigir un aparato autocrático que complementó la cultura fuertemente autoritaria de nuestra clase dirigente. Dotado de amplios recursos y una organización superior, el Ejército con el tiempo, se convirtió en una corporación poderosa con leyes, reglamentos, valores y costumbres contrarios al estilo de vida de la sociedad democrática" ${ }^{40}$

Polino además mencionó un informe encomendado por el Presidente de los Estados Unidos a una comisión presidida por el Secretario de Estado, Thomas Gates, que ya en 1970 ponderó el "ahorro" presupuestario provisto por el sistema de voluntarios frente a los "costos ocultos" de la conscripción que obligaba al Estado anualmente a invertir cuantiosas sumas de dinero y esfuerzos para instruir a nuevas camadas de soldados. Para el diputado socialista:

“En la Argentina menos del dos por ciento de los conscriptos se reincorpora. El corto período de servicio representa otra deficiencia de la conscripción. Un gobierno democrático no puede obligar a los jóvenes conscriptos a un servicio de más de un año. Estos dos factores, el bajo porcentaje de reincorporación y el breve período de adiestramiento, demandan una erogación anual de adiestramiento innecesariamente alta [...] Este informe

${ }^{39}$ DSCD, 14 de septiembre de 1994, p. 2194.

${ }^{40}$ DSCD, 14 de septiembre de 1994, p. 2185. 
[de la Comisión Gates] luego señala: 'Anacrónico e incompatible con la ética democrática, el servicio militar debe ser suprimido y reemplazado por una fuerza voluntaria. La conscripción, que aumenta innecesariamente el poder del Estado sobre el individuo, resulta costosa, injusta y divisiva". ${ }^{41}$

Desde una adscripción político-ideológica radicalmente diferente, el diputado Álvaro Alsogaray también estaba a favor de un sistema de voluntarios. Decía que la UCeDe ya había optado por esto último en su programa político de 1982, pero el mismo debía complementarse con una conscripción obligatoria de tres meses para que todos los ciudadanos, "sin distinción de categorías", contribuyeran en su totalidad a la formación de reservas para la defensa nacional. ${ }^{42}$.

También el diputado Raúl Roque Topa (Fuerza Republicana/Tucumán) criticaba la "selectividad" operada en la aplicación práctica del reclutamiento de ciudadanos en el sistema de conscripción, que recaía por el azar del sorteo en un porcentaje menor de los jóvenes de una "clase" $y$, entre estos, principalmente sobre quienes no disponían de recursos económicos, sociales y/o políticos para evitar el cumplimiento del servicio militar. Topa definía la conscripción como un sistema "discriminatorio" que "quiebra el principio de igualdad ante la ley", a pesar que en 1901 había sido concebida justamente para terminar con ese criterio "discriminatorio". ${ }^{43}$ Del mismo modo, el diputado Antonio Erman González (PJ/Capital Federal) refirió a la "injusticia y desigualdad" que el servicio militar obligatorio producía en los hechos a comienzos de la década de 1990:

“Antes entre el 80 y 90 por ciento de la ciudadanía realizaba la conscripción, y hoy solamente la cumple el 8 por ciento. Es decir que el 92 por ciento restante no hace el servicio militar obligatorio, como consecuencia de una bolilla que en el sorteo provoca una profunda desigualdad de los ciudadanos ante la ley. Antes era el orgullo de haber pertenecido -aunque sea por un año- a las fuerzas armadas; hoy se considera a la bolilla que puede determinar en un sorteo que una persona se incorpore a las fuerzas armadas como un cuco que puede hacer que el ciudadano pierda un año entre comillas, al hacer el servicio militar". ${ }^{4}$

También el diputado Ramón Francisco Giménez (PJ/Formosa) ponderó las funciones cumplidas en pasado por la conscripción "para la grandeza de la 
patria y la felicidad del pueblo". Como ex-soldado del Regimiento 29 de Infantería de Monte en Formosa dijo que, con otros jóvenes de su generación, en la conscripción había aprendido las "cualidades y virtudes viriles, patrióticas, guerreras, cargadas de un sentimiento sublime hacia la Nación que nos cobija". Comparaba su importancia histórica para la educación de los jóvenes argentinos con la establecida en 1884 por la Ley 1.420 de Educación Común que -decía- solo fuera "superada hace poco tiempo con la Ley Federal de Educación" de 1993. ${ }^{45}$ El diputado Víctor Peláez también había sido conscripto en su juventud, pero valoraba aquella experiencia de un modo radicalmente distinto. Para Peláez la conscripción era un sistema "violatorio de la libertad, de la integridad física, de la dignidad" y "pone en peligro de la vida". También era "inconstitucional" pues "crea un régimen de esclavitud, si bien legal y temporario". Para Peláez el deber de participar en la defensa no era un principio que se hiciera valer por encima de los intereses y deseos personales del ciudadano; por ello sostenía que la conscripción era un régimen de "esclavitud":

“...Cuando a una persona se le obliga a hacer lo que no quiere, y como si esto fuera poco no se la remunera, estamos ante un sistema de esclavitud. No se trata de un servicio sino de una servidumbre. Habíamos creado un régimen de esclavitud y no nos dábamos cuenta. Este es un aspecto que he charlado con los señores militares. He tenido una experiencia muy desgraciada del ejército. Tuve que cortar el césped con las manos y cuando preguntaba por qué no se ponía un jardinero en los cuarteles, teniendo en cuenta que todos poseían parques, obtenía como explicación que era muy oneroso. Entonces la conclusión es que se busca mano de obra barata. ¿Para qué sacrificamos a nuestros hijos, como me sacrifiqué yo? ¿Para qué tener mano de obra barata? Es el mismo argumento utilizado en los Estados Unidos en la época de Lincoln ¿Cómo iban a dejar libres a los negros? ¿Quién iba a levantar la cosecha de algodón y de caña de azúcar? Necesitaban mano de obra barata. Con esos argumentos creamos un sistema de esclavitud en nuestras fuerzas armadas para nuestros propios muchachos. Es algo inadmisible" ${ }^{46}$

Anticipándose a las críticas de quienes argumentaban que el servicio militar era un deber constitucional del ciudadano, Peláez decía que a diferencia de otras prestaciones -como la "actividad censal, la electoral o la testimonial"en las postrimerías del siglo XX la conscripción era una "carga pública" 
"imposible de soportar", "un abuso por parte del Estado" "creyendo ser dueño de las personas". ${ }^{47}$

La diputada Graciela Fernández Meijide también hizo una evaluación crítica de la concepción y experiencia de la conscripción en el siglo XX. Sostuvo -en respuesta implícita a Bussi- que había sido "un poderoso instrumento de moralización pública y antídoto contra el cosmopolitismo" del inmigrante. Decía que la ley de 1901 consideró al inmigrante que masivamente llegaba a la Argentina como:

“...sospechoso de traer inmoralidad pública y de mezclar inconvenientemente su sangre con la que estaba establecida [...] Nada de considerar las etnias diferentes con sus propias características. Había que fusionarlas. Homogeneización y disciplinamiento de la sociedad se buscaba a través del servicio militar obligatorio" ${ }^{48}$

Por su parte, el diputado Sergio Montiel (UCR/Entre Ríos) apoyaba el proyecto en disidencia parcial. En su exposición consideró necesario inscribir las innovaciones legislativas en curso en el marco de los cambios históricos que definieron el sistema de reclutamiento y conformación de la tropa de las Fuerzas Armadas, en particular del Ejército, desde comienzos del siglo XIX hasta fines del XX. Decía que la historia del Ejército Argentino y su relación con el reclutamiento de ciudadanos se podía dividir en tres etapas: 1810/1901, 1901/1994 y desde 1994 en adelante:

“La primera es la del Ejército Argentino nacido el 29 de mayo de 1810 en virtud de un decreto firmado por el secretario de defensa Mariano Moreno, por el que establece la presencia de los ciudadanos en la actividad militar. Este período se extiende con variantes hasta la sanción de la Ley Riccheri en 1901. Desde ese momento hasta el presente rige un sistema totalmente distinto. Es verdad que nuestro viejo Ejército -como aquí se ha dicho- tenía defectos vinculados con las levas, pero también es cierto que cumplió acabadamente en sus extremos finales con lo establecido por la Constitución en cuanto a que los ciudadanos deben armarse en defensa de la Patria. Lo hizo de una manera especial con sus guardias territoriales según las funciones otorgadas a los gobernadores de provincia como representantes de órganos de gobierno federal, con las reservas compuestas por veteranos de las distintas guerras que se habían librado y

${ }^{47}$ DSCD, 14 de septiembre de 1994, p. 2201.

${ }^{48}$ DSCD, 14 de septiembre de 1994, pp. 2201-2202. 
con un grupo de voluntarios. Esa era la composición del ejército de línea del país". ${ }^{49}$

Montiel recordó que el proyecto de ley del Riccheri "mereció dictamen adverso" de los diputados -algunos de ellos militares- que defendían el sistema consagrado por la Constitución de 1853 que combinaba, por un lado, un "pequeño núcleo de fuerzas armadas permanentes", de "voluntarios" integrantes del "ejército de línea"; y, por otro, las "milicias" de ciudadanos organizados "en defensa de la patria". Contrariamente con aquella tradición miliciana de la "tradición argentina", "sudamericana" y "americana", la ley de 1901 se había inspirado en el "modelo prusiano" de ejército profesional que eliminó "las guardias territoriales y las milicias" e hizo de las reservas "un instrumento del propio ejército" y "no de la sociedad". ${ }^{50}$ Aun así, en el sistema de conscripción del siglo XX los ciudadanos continuaron cumpliendo con sus “obligaciones de defensa de la patria". Ahora bien, preguntaba qué ocurriría cuando la prestación se volviera enteramente voluntaria. Montiel no se oponía al nuevo sistema, pero advertía el problema que acarreaba: ¿Quiénes estarían dispuestos a armarse en defensa del país cuando esto fuera necesario? ¿Cómo se conformarían las reservas de ciudadanos militarmente instruidos para la defensa? ¿Qué relaciones mantendría la dirigencia política y la sociedad argentina con esas nuevas Fuerzas Armadas integradas exclusivamente por profesionales? ${ }^{51}$

${ }^{49}$ DSCD, 14 de septiembre de 1994, p. 2179.

${ }^{50} D S C D, 14$ de septiembre de 1994, pp. 2179-2180. Las tensiones a las que refería el diputado Montiel entre, por un lado, el modelo de un ejército profesional y permanente fuerte con capacidad de reclutar amplios sectores de la población por medio del sistema de conscripción y, por otro, el modelo del ciudadano-soldado organizado en milicias, había tenido una conflictiva historia en los siglos XVII y XVIII en Inglaterra y América del Norte. MORGAN, Edmund La invención del pueblo. El surgimiento de la soberanía popular en Inglaterra y Estados Unidos, Siglo Veintiuno, Buenos Aires, 2006. En tanto que la experiencia de la Francia revolucionaria de fines de siglo XVIII se ha asociado con el sistema de reclutamiento masivo obligatorio conforme a otro modelo de ciudadano-soldado. ROSANVALLON, Pierre La consagración del ciudadano. Historia del sufragio universal en Francia, Instituto Mora, México, 1999. Por último, el modelo prusiano es uno expresivo del desarrollo militar de Prusia en el siglo XIX con un ejército profesional con capacidad de reclutamiento y disponibilidad de reservas para la defensa mediante el recurso a un servicio militar general impuesto sobre la población de una sociedad militarizada. BEST, Geoffrey Guerra y sociedad en la Europa revolucionaria. 1770-1870, Ministerio de Defensa, Madrid, 1990.

${ }^{51}$ La Ley de Servicio Militar Voluntario no definió cómo se conformaría el sistema de reservas para la defensa, señalando en su articulado que dicha cuestión ería objeto de una ley específica que nunca se sancionó. "Articulo 11ํ-Las reservas constituirán el componente ineludible del Sistema Nacional de Defensa, su organización, estructura, funcionamiento y capacitación se regirán por la ley que se dicte a tal efecto. Artículo $12^{\circ}$-La reserva del Sistema de Defensa Nacional se convocará con el propósito de completar, cuando así se disponga, los efectivos del Ejército, la Armada y la Fuerza Aérea, o los efectivos que se asignen a tareas de protección y defensa civil". http://infoleg.mecon.gov.ar/ Consultado en línea el 01 de junio de 2015. 
Del mismo modo, el diputado Francisco Durañona y Vedia consideraba que la suspensión de la conscripción en tiempos de paz dejaba abierto problemas no resueltos por el proyecto:

"Qué sucedería si no hubiese interés en esta cuestión, si no fuera atractiva la retribución, si a nadie interesara toda esta larga lista de beneficios [...] Cuál es la aceptación que tiene en la comunidad este servicio: puede ser que no tenga ninguna, que tenga mucha o que ocurra lo que expresa el señor diputado Polo respecto de que esto se pueda pensar como un sustituto de empleo" ${ }^{52}$

Para Durañona y Vediasi no se legislaba sobre la formación de las reservas, si los ciudadanos solo optaban voluntariamente por el servicio militar en pos de beneficios utilitarios inmediatos, pues entonces el país no dispondría de ciudadanos con adiestramiento militar y quizá tampoco la cantidad suficiente para su defensa.

\section{La conscripción y la última dictadura}

La concepción del ciudadano y del soldado que se procuró plasmar en el proyecto de ley comprendía una referencia enfática al reconocimiento de los derechos humanos. Dicha cuestión gravitó a propósito de su artículo $2^{\underline{a}}$. En su intervención el diputado radical Jesús Rodríguez sostuvo que el proyecto no había enfatizado suficientemente el resguardo por los "derechos del soldado" y contra "los abusos sobre los conscriptos". Recordaba que en 1992, en ocasión de la presentación de un proyecto de servicio militar voluntario, el diputado radical Victorio Bisciotti dijo que:

“...en los últimos años los cuadros dirigentes de las fuerzas armadas y los estados mayores manejan un concepto distinto de lo que es el soldado. Valga como ejemplo la forma en que comenzó a respetarse al conscripto quien no puede ser humillado o degradado. Para que se me entienda bien, ningún soldado tiene la obligación de limpiar montañas de estiércol o hacer el famoso salto rana -no se si usted, señor presidente, lo tuvo que hacer pero a muchos de nosotros nos tocó vivir esa experiencia-, porque una cosa es el adiestramiento y otra que el soldado no sea respetado en su integridad de ser humano. Este proyecto de ley tiende a que esto sea así y los estamentos superiores de las fuerzas armadas con los cuales hemos dialogado en la Comisión de Defensa están llegando a este

${ }^{52}$ DSCD, 14 de septiembre de 1994, p. 2192. 
grado de modernidad en el respeto a los derechos de los ciudadanos". ${ }^{53}$

Y seguidamente el diputado Rodríguez agregaba:

“Entendemos entonces que en pos de dar muestras claras del interés legislativo de evitar abusos y de incitar al voluntariado con mayores garantías, que desde nuestras bancas podamos brindarles a los ciudadanos que opten, debemos incorporar además un artículo nuevo que diga lo siguiente [...] Toda actividad relativa al denominado 'orden cerrado' así como también toda otra actividad que involucre cualquier aspecto de la relación mando-obediencia entre oficiales y suboficiales, y entre ellos y soldados conscriptos y/o voluntarios de las fuerzas armadas y de seguridad de la Nación, deberá respetar la vida e integridad física y moral de los inferiores o subordinados, asegurándose que las mismas se desarrollen en condiciones de dignidad y respetando los derechos humanos básicos. Lo anterior es aplicable tanto en tiempos de paz como en tiempos de guerra sea en acto de servicio o no". ${ }^{54}$

Esta propuesta de Rodríguez convergió con la de otros diputados y fueron incorporadas en el artículo $2^{\mathrm{o}}$ de la ley. ${ }^{55} \mathrm{Su}$ intervención era expresiva de percepciones de amplios sectores de la población que cuestionaban las condiciones en que se cumplía el servicio militar obligatorio y el trato que muchas veces recibían los conscriptos de oficiales y suboficiales. Pero también remitían a la experiencia reciente del terrorismo de Estado durante la dictadura del autodenominado "Proceso de Reorganización Nacional" entre los años 1976-1983. En este sentido, a comienzos de la década de 1990 cualquier tentativa de sostener la conscripción -aunque fuera en un sistema mixto de voluntarios complementado por conscriptos- habría recibido el rechazo de diversos sectores de la dirigencia política y de la sociedad civil.

${ }^{53}$ DSCD, 14 de septiembre de 1994, p. 2169.

${ }^{54}$ DSCD, 14 de septiembre de 1994, pp. 2169-2170.

${ }^{55} \mathrm{El}$ artículo $2^{\mathrm{o}}$ finalmente quedó redactado del siguiente modo: “Los derechos que resguardan la dignidad humana, reconocidos, adheridos y practicados por nuestro país, constituyen la base fundamental de dictado y ordenamiento para las normas particulares de procedimiento, que deberán ser respetados y en su omisión exigidos por todos los ciudadanos. Las leyes, reglamentos militares y convenios internacionales aceptados, que regirán las actividades y comportamientos humanos en el ámbito de las fuerzas armadas, comprenderán y asegurarán los resguardos necesarios a los ciudadanos que presten servicio en el Sistema Nacional de Defensa así como también a los objetivos y fines que sean pertinentes con los intereses supremos de la Nación". http://infoleg.mecon.gov.ar/ Consultado en línea el 01 de junio de 2015. 
De igual modo el diputado socialista Héctor Polino consideraba vital preservar los derechos humanos del ciudadano-soldado. Si sobre esto Jesús Rodríguez invocaba precedentes legislativos de su correligionario radical Bisciotti, Polino recordaba al diputado socialista Alfredo Bravo proponiendo la creación de un "Comisionado del Congreso para las Fuerzas Armadas" cuyas funciones serían garantizar los derechos humanos del personal militar atendiendo "los reclamos o denuncias" y velando "por el correcto cumplimiento de las disposiciones constitucionales y legales que protegen los derechos humanos de las personas involucradas". ${ }^{56}$ Contrariamente con este énfasis, para el diputado de la UCeDe, Francisco de Durañona y Vedia, aquellas referencias del artículo $2^{\circ}$ eran "sobreabundantes", pues entendía que los derechos del ciudadano-soldado estaban "consagrados desde siempre por la Constitución Nacional". En su opinión:

"Pareciera que cada vez que el Congreso de la Nación se aboca al tratamiento de asuntos relativos a las fuerzas armadas -se pueden mencionar como antecedentes las leyes de defensa nacional y de seguridad interior- tienen que consignar estas visiones o prevenciones para que se cumpla el orden constitucional, para que las ordenes que se impartan estén dentro de las normas jurídicas, para que se respeten los derechos humanos [...] Tenemos que suponer que las fuerzas armadas están incorporadas al orden institucional como se ha dicho; que en los cuadros que integran las fuerzas armadas hay personas que están siguiendo una carrera, con todas las dificultades, el énfasis y la ilusión que ello importa; que hay hombres jóvenes que se han incorporado a las filas de nuestras fuerzas armadas y ven que cada vez que la ley se dirige a estas instituciones fundamentales de la República tienen que recordar en forma de prevención el principio de cumplimiento de las normas que rigen los derechos fundamentales y el respeto a la Constitución" ${ }^{57}$

Del mismo el líder de la UCeDe Álvaro Alsogaray interpretaba que el proyecto reflejaba "una actitud anti-fuerzas armadas". En particular, consideraba el artículo $2^{\circ}$ como "declamatorio, innecesario y, al mismo tiempo, revelador de ese espíritu de sospecha hacia las instituciones militares". También tenía por innecesario el artículo $8^{\circ}$ que afirmaba que los soldados estaban "obligados al cumplimiento estricto de las leyes y reglamentos militares",

56 DSCD, 14 de septiembre de 1994, pp. 2187-2188.Sobre la figura de ese "comisionado", "defensor" u "ombudsman militar", véase: SOPRANO, Germán "El ombudsman militar: conflictos entre derechos ciudadanos y orden castrense en la Argentina del siglo XX", en: Revista Quaestio Iuris, vol. 8, 끄. 2, Rio de Janeiro, 2015, pp. 718-734.

${ }^{57}$ DSCD, 14 de septiembre de 1994, pp. 2219-2220. 
“coherentes con las leyes supremas de la Nación, con las del Sistema Nacional de Defensa y que sirvan a las actividades propias del ámbito institucional específico donde se encuentren incorporados”. Alsogaray preguntaba: “¿Por qué sospechar que las órdenes que se van a dar son contrarias a esos grandes postulados indicados en el citado artículo?". ${ }^{58}$ Para el diputado Antonio Erman González (PJ/Capital Federal), en cambio, aquellos énfasis no eran baladíes, pues en la Argentina: "No siempre se dieron órdenes que significaran respetar la Constitución, los derechos humanos y las leyes". ${ }^{59}$ Con ello González aludía a las órdenes impartidas por la conducción de las Fuerzas Armadas durante la última dictadura en el marco de la "lucha contra la subversión" y que fueran objeto de causas penales desde la "apertura democrática" de diciembre de 1983 hasta su clausura, primero, con la Ley de Punto Final de 1986 y la Ley de Obediencia Debida de 1987 y, posteriormente, con los indultos del presidente Carlos Menem de 1989-1990 otorgados a jefes militares condenados y/o procesados por crímenes de lesa humanidad.

\section{Soldados voluntarios, objetores de conciencia e infractores al servicio militar}

¿Quiénes podían ser soldados voluntarios? Para la diputada Ana Raquel Kessler todos los ciudadanos argentinos, varones o mujeres. ${ }^{60}$ La incorporación de mujeres constituía una novedad, pues el decreto-ley 17.531 de 1967 reconocía su participación en el servicio militar en tanto ciudadanas pero las excluía de la conscripción.Para Jesús Rodríguez los ciudadanos podían ser voluntarios cualquiera fuera su estado civil: "soltero, casado y/o de familia numerosa, divorciado o viudo"; y los analfabetos ingresarían completando sus estudios durante el servicio. Rodríguez llevaba la edad máxima para la prestación hasta los 35 años, una edad que los militares no recomendaban pues, decían, un adulto no tiene disposición para aprender y socializarse en la disciplina castrense. ${ }^{61}$ Por su parte, el diputado radical Sergio Montiel propuso incorporar a los ciudadanos argentinos naturalizados, estimando que su exclusión en la ley de 1901 había sido consecuencia del "temor reverencial" a "los chilenos que han cruzado la frontera, ingresaron a nuestro país, pidieron carta de ciudadanía y habitan como argentinos". Consideró esta exclusión inconstitucional y un

\footnotetext{
58 DSCD, 14 de septiembre de 1994, p. 2204.

${ }^{59}$ DSCD, 14 de septiembre de 1994, p. 2204.

60 Asimismo debe tenerse en cuenta que por el artículo $5^{\mathbf{o}}$ de la ley los soldados voluntarios debían "respetar el principio de neutralidad política de las fuerzas armadas", se abstendrían de realizar "actividades políticas o sindicales", y podía ejercer "el derecho a voto" de acuerdo a lo regulado por la Ley Nacional Electoral. http://infoleg.mecon.gov.ar/ Consultado en línea el 01 de junio de 2015.

${ }^{61}$ La ley estableció los 28 años como edad máxima para permanecer como soldado voluntario.
} 
"grave error, porque nuestra legislación equipara a todos los argentinos naturalizados o nativos". ${ }^{62}$

Hemos visto previamente la intervención del diputado Durañona y Vedia cuando preguntaba si la nueva ley atraería a suficiente cantidad de jóvenes para cubrir el cupo de soldados. El diputado del MODIN, Luis Nicolás Polo, era pesimista: no se llegaría a completar los "escasos" requerimientos estimados por las autoridades militares que, según dijo, rondaban los 26 mil soldados. Quiénes querrían ofrecer sus servicios como soldados voluntarios si los "jóvenes" y "sus padres" festejaban con "alegría" la suspensión de la conscripción $\mathrm{y}$, peor aún, si se consideraba los magros estímulos y salarios ofrecidos por ese servicio militar. Esas frustraciones en las "vocaciones" de los soldados también eran padecidas -decía- por oficiales y suboficiales de las Fuerzas Armadas. En consecuencia, el país se sumiría en una total indefensión respecto de aquellas amenazas externas que requirieran del instrumento militar.

En el proyecto de ley se procuraba atemperar este problema ofreciendo beneficios previsionales $\mathrm{u}$ otros estímulos como el acceso prioritario como personal de la administración pública nacional, la justicia federal o las fuerzas de seguridad, una vez que los soldados se dieran de baja del servicio en las Fuerzas Armadas. Sin embargo, esos estímulos y beneficios -incorporados a la ley- fueron rechazados por legisladores de diferentes orientaciones políticoideológicas en el debate parlamentario. ${ }^{63}$ Así pues, el diputado Francisco Durañona y Vedia decía que:

${ }^{62}$ DSCD, 14 de septiembre de 1994, p. 2182. El artículo $8^{\text {o }}$ de la ley definió el perfil de los postulantes del siguiente modo: “a) Ser ciudadanos argentinos varones o mujeres, hábiles, nativos, por opción o naturalizados; b) Ser de estado civil soltero; c) Tener entre 18 y 24 años de edad; d) Tener autorización de representante legal, en caso de ser menores de edad; e) Cumplir las condiciones de educación y aptitudes psicofísicas que se establezcan en la reglamentación; f) Satisfacer las exigencias que en materia de cursos y pruebas de ingreso se determinen por parte de la fuerza respectiva". http://infoleg.mecon.gov.ar/ Consultado en línea el 01 de junio de 2015. ${ }^{63}$ El artículo 9o de la ley estableció los siguientes beneficios: “a) Los voluntarios percibirán por la prestación del servicio la retribución mensual, cobertura asistencial y beneficios que se establezcan oportunamente; b) Se les otorgarán condiciones preferenciales o puntaje adicional para su ingreso a la administración pública nacional y a la Municipalidad de la Ciudad de Buenos Aires, Poder Judicial de la Nación y Poder Legislativo Nacional, y para la adquisición de viviendas en los planes nacionales y municipales. Se invita a las provincias a adherirse a lo establecido en el presente inciso y a solicitar a las municipalidades de sus respectivas jurisdicciones seguir igual temperamento; c) El cumplimiento del SMV generará los beneficios y ventajas que fije la reglamentación para el ingreso a todas las fuerzas de seguridad, policiales y al Servicio Penitenciario; d) Las fuerzas armadas podrán certificar la capacidad laboral en aquellos casos que desempeñen o sean capacitados para oficios o tareas de aplicación civil; e) Se otorgarán facilidades para el ingreso a los institutos militares; f) Los años del SMV otorgarán antigüedad a los fines de la jubilación". http://infoleg.mecon.gov.ar/ Consultado en línea el 01 de junio de 2015. 
“...me cuesta creer que por el hecho de que una persona esté un año incorporada y retribuida por el servicio tenga derecho a todos estos privilegios que muchas veces han venido a solicitar a esta Cámara otros sectores o ex-combatientes, limitándose esta última a otro tipo de reconocimiento..."64

Del mismo modo para el diputado Gustavo Adolfo Green (PJ/Provincia de Buenos Aires) eran beneficios "inaceptables en una república", y para el diputado socialista Alfredo Bravo "un contrato por un salario voluntario y para prestar un servicio" no debía redundar en tales privilegios excepcionales como ciudadanos. ${ }^{65}$

Sin embargo, el diputado justicialista Antonio Erman González, ex Ministro de Defensa entre 1991-1993, consideraba que el reclutamiento de voluntarios sería completado sin problemas:

"Estamos hablando de jóvenes de 18 a 24 años de edad; es decir que abarca a seis clases. Si tomamos un número redondo de trescientos mil jóvenes por clase, estaríamos hablando de una convocatoria de un millón ochocientos mil jóvenes argentinos. $\mathrm{Si}$ solamente respondiera el 1,5 por ciento, estaríamos cubriendo con creces las necesidades planteadas para 1995 en materia de número de efectivos para cubrir el servicio militar voluntario". ${ }^{66}$

Recordó además que la defensa no era solo responsabilidad de los profesionales de las Fuerzas Armadas sino una "obligación y deber de todos los argentinos, cualquiera sea su condición social o política" ${ }^{67}$ En tal caso siempre quedaba al alcance del Estado el reclutamiento obligatorio, pues, el artículo 21 de la Constitución establecía que la defensa era una obligación ciudadana y con el servicio militar voluntario la conscripción no se abrogaba sino suspendía.

Para poder disponer de ciudadanos instruidos para la defensa en circunstancias excepcionales, el diputado Jesús Rodríguez insistía en la necesidad de regularla composición de las reservas, cuestión soslayada en el presente proyecto, pero que fue objeto del proyecto de Antonio Berhongaray (UCR/La Pampa). Para este último la formación de las reservas se debía producir con un sistema de "instrucción para la defensa" obligatorio para todos los ciudadanos varones mayores de 18 años y opcional para mujeres; comprendiendo instrucción "militar armada" y "militar no armada" de tres

\footnotetext{
${ }^{64}$ DSCD, 14 de septiembre de 1994, p. 2190. Durañona y Vedia se refería a los "ex-combatientes" o "veteranos" de la guerra de Malvinas.

${ }^{65}$ DSCD, 14 de septiembre de 1994, pp. 2223-2226.

${ }^{6}$ DSCD, 14 de septiembre de 1994, p. 2205.

${ }^{67} D S C D, 14$ de septiembre de 1994, p. 2205.
} 
meses de duración, e "instrucción para la protección civil" de igual cantidad de tiempo. ${ }^{68}$

Una discusión específica suscitaron los "objetores de conciencia". ${ }^{69}$ Se trataba de legislar sobre los ciudadanos que rechazarían la prestación militar cuando fueran convocados obligatoriamente en una situación de guerra o ante su inminencia. El diputado Toma señaló que esta era una cuestión vital, pues:

"Ante la eventualidad de una crisis donde haya que cumplir con el precepto constitucional de que todo argentino debe armarse en defensa de la patria [...] hemos reivindicado un derecho privadísimo, un derecho humano sustancial, como es el de la libertad de conciencia [...]que quien tenga profundas convicciones como para no empuñar un arma, sea respetado por la sociedad aún en una situación de crisis [...] la norma no lo exime de encarar una tarea riesgosa en caso de crisis, porque estaríamos vulnerando contrario sensu el principio de igualdad ante la ley, más allá de la convicción que cada uno profese".

En cambio, el diputado Álvaro Alsogaray criticaba la amplitud con que se exceptuaba a los objetores de conciencia: "Lo de religioso es aceptable y lo de moral también, pero en cuento a lo filosófico me parece que se les va la mano a los legisladores". ${ }^{70}$ También se oponía a que en tiempos de paz los infractores de la Ley de Servicio Militar Voluntario se sometieran a jurisdicción federal y no al fuero militar, pues entendía que esto era "absolutamente contrario a la disciplina y el ejercicio de la autoridad militar". ${ }^{71}$

Por último, el proyecto establecía una "amplia amnistía para los infractores" a la Ley de Servicio Militar. El diputado Toma definía esto como un "acto de justicia" antes que una concesión, pues:

"Muchos jóvenes argentinos, e incluso sus padres, se fueron de este país en épocas más duras, cuando muchos de los que estábamos aquí éramos perseguidos, secuestrados o torturados, en las mazmorras de la dictadura. Hay muchos jóvenes que nacieron afuera, y muchos que se fueron y no volvieron porque

\footnotetext{
${ }^{68}$ DSCD, 14 de septiembre de 1994, p. 2208.

${ }^{69}$ DSCD, 14 de septiembre de 1994, p. 2176. Los artículos 20 y 21 de la ley definieron un servicio social sustitutorio para ciudadanos que por "profundas convicciones religiosas, filosóficas o morales, opuesta en toda circunstancia al uso personal de armas o a la integración de cuerpos militares" no prestaran servicio militar cuando fuera preciso recurrir excepcionalmente a la conscripción. Ese servicio comprendería: “a) Actividades de protección y defensa civil, según prescriba la ley respectiva; b) Servicios sanitarios, sociales o educativos; c) Conservación del medio ambiente, mejora del medio rural y protección de la naturaleza". http://infoleg.mecon.gov.ar/ Consultado en línea el 01 de junio de 2015.

70 DSCD, 14 de septiembre de 1994, p. 2188.

${ }^{71}$ DSCD, 14 de septiembre de 1994, p. 2188.
} 
tienen problemas, ya que son infractores del servicio militar. También queremos dar respuesta a ellos. Se trata, insisto, de una reivindicación de la democracia para con el pueblo que sufrió la dictadura. Por eso hago hincapié en estos temas. No nos hemos olvidado quiénes somos, de dónde venimos y hacia dónde vamos. Aunque a veces quienes estamos sentados en estas bancas tenemos que aceptar a regañadientes algunos condicionamientos que la realidad, por dura que sea, nos impone, que quede claro que por lo menos los que desde estas bancas hemos planteado este proyecto de ley no perdimos nuestra condición de peronistas y nuestro profundo compromiso con la justicia social, y la reivindicación de la juventud y del resto de la sociedad argentina (Aplausos)" ${ }^{72}$

Toma introducía una vez más en el debate parlamentario la comprensión de esas relaciones entre los ciudadanos y sus prestaciones militares en el siglo XX como unas atravesadas por la represión estatal en la última dictadura.

\section{Conclusiones}

A comienzos del siglo XVI Nicolás Maquiavelo argumentó en favor de la conveniencia para la república de contar con fuerzas militares propias conformadas por ciudadanos. Entendía que la alternativa entre este recurso o el de tropas mercenarias implicaba distintas definiciones político-ideológicas y consecuencias militares. Un ejército de ciudadanos no solo garantizaba un tipo diferente de legitimidad y reconocimiento social, sino también ofrecía hombres más eficientes en combate pues los ciudadanos-soldados peleaban por objetivos caros a los intereses de su sociedad. Contrariamente, para las fuerzas mercenarias la guerra era un negocio mediante el cual obtenían su propio sustento; los mercenarios hacían de la guerra un fin en sí mismo que, convenientemente, prolongaban en el tiempo. Las recomendaciones de Maquiavelo fueron contemporáneas de las pretensiones de las monarquías europeas por hacerse del monopolio de la violencia legítima (según la clásica expresión de Max Weber) en circunstancias en las cuales no abandonaron los mercenarios, pero propiciaron también la incorporación de súbditos. Los Estados imperiales y nacionales del siglo XIX consolidaron esta última tendencia con la conscripción de ciudadanos y la profesionalización del cuadro de oficiales y suboficiales de sus Ejércitos. Por entonces, otro autor de referencia, Carl von Clausewitz, reflexionó acerca de las relaciones entre el Gobierno que concibe la guerra como un instrumento de la política, el Ejército

${ }^{72}$ DSCD, 14 de septiembre de 1994, p. 2177. 
como su brazo ejecutor, y el Pueblo como portador de la violencia primordial, odio y enemistad que alimentaba el desarrollo de la guerra. ${ }^{73}$

A fines del siglo XX las circunstancias históricas había cambiado, pero aquellas concepciones de Maquiavelo y von Clausewitz -fundamentales en la génesis y desarrollo de la teoría política moderna- todavía influían en los posicionamientos de los legisladores argentinos en el debate por Ley de Servicio Militar Voluntario. En torno del consenso general a favor de la suspensión o abrogación de la conscripción obligatoria, gravitaba una discusión acerca de la redefinición en la democracia de las relaciones entre los conceptos de ciudadanía -con sus derechos y obligaciones- y de soldado, así como los vínculos que debían establecerse entre la sociedad argentina y sus Fuerzas Armadas.

La opción por el servicio militar voluntario en tiempos de paz suspendió la aplicación del servicio de las armas como deber del ciudadano argentino e implicó además el reconocimiento pleno de la ciudadanía de las mujeres habilitándolas a incorporarse al nuevo sistema. Si la alternativa de la conscripción permaneció en el texto de la ley como un recurso excepcional en tiempos de guerra o ante un escenario de conflicto bélico inminente, fue porque primó entre los legisladores la legitimidad de la obligación constitucional del ciudadano de armarse en defensa de la patria. Dicha definición, no obstante, fue objetada por algunos diputados que consideraban esa persistencia latente de la conscripción como un resabio autoritario del pasado. En tanto que la ley, asimismo, reconoció en su plexo la posibilidad de un servicio social sustitutorio para objetores de conciencia. Señalemos además que esa reformulación de los derechos y deberes del ciudadano estaba asociada la definición del concepto de soldado voluntario, ponderado por algunos diputados no solo como adecuado para la sociedad democrática de fines del siglo $X X$, sino como un recurso humano eficaz en el proceso de modernización y profesionalización de las Fuerzas Armadas contemporáneas.

\footnotetext{
${ }^{73}$ Somos conscientes de que desde el punto de vista de una historia intelectual y conceptual la invocación de la concepción de Maquiavelo acerca de las relaciones entre ciudadanía y prestaciones militares resulta históricamente extemporánea para comprender el presente debate, toda vez que -como nos fue observado con precisión por un evaluador- la problemática de los ejércitos en la modernidad temprana no puede ser planteada con independencia de las múltiples formas de gobierno, de recuperación de la tradición clásica y del surgimiento de la soberanía en situaciones concretas de las formaciones sociales europeas de la época. Sin embargo, la invocación viene a cuento porque en la perspectiva de von Clausewitz se reconoce una reflexión diferente de aquella postulada por Maquiavelo, en la medida en que su concepción de la trinidad Gobierno/Ejército/Pueblo comprendía las transformaciones sociales y políticas producidas tras la Revolución Francesa: la "leva en masa del pueblo" y, posteriormente, la articulación el sufragio masculino y el servicio de armas que hicieron realidad el ideal de la "nación en armas". LYNN, John "Naciones en armas, 1763-1815", en G. Parker (ed.) Historia de la guerra, Akal, Madrid, 2010, pp. 195-224.
} 
La reflexión sobre pasado estuvo fuertemente presente en el debate no solo para dar cuenta de las comparaciones entre 1901 y 1994 y en relación con los reconocimientos y críticas sobre la eficacia social del sistema de conscripción; también como un llamado de atención respecto de las violaciones a los derechos del ciudadano y del soldado producidas -para algunos excepcionalmente, para otros por regla general- durante la aplicación del servicio militar obligatorio en el siglo $X X$, situación que había alcanzado una enorme visibilidad pública a raíz del asesinato el soldado Carrasco.

Finalmente, tal como señalamos al comienzo del artículo, la suspensión de la conscripción obligatoria y adopción del sistema de soldados voluntarios asumió en la Argentina características específicas, configuradas por la crisis por colapso de la última dictadura y la depreciación del peso político y corporativo de las Fuerzas Armadas en el Estado y la sociedad argentina, la severa reducción presupuestaria en el área de defensa nacional, la afirmación de un movimiento de opinión pública contrario a la conscripción, y la percepción en la dirigencia política y en amplios sectores de la ciudadanía de que no existían importantes amenazas militares externas en el escenario de la pos-guerra Fría y de cooperación regional en el Cono Sur. No obstante, es necesario no perder de vista -como lo estaba para algunos legisladores en 1994- que ese cambio reconocía antecedentes en las transformaciones ocurridas en los Estados Unidos desde la década de 1970 y era contemporáneo de aquellas que comenzaban a producirse en Europa en la década de 1990.

Bernal / La Plata, marzo de 2016 